\title{
PROTECTION OF WOODEN MATERIALS AGAINST BIOLOGICAL ATTACK BY USING NANOTECHNOLOGY
}

\author{
Michal Havrlik ${ }^{a, *}$, Pavla Ryparová ${ }^{b}$ \\ a Department of Physics, Faculty of Civil Engineering, Czech Technical University in Prague, Thakurova 7, 166 \\ 29 Prague 6, Czech Republic \\ ${ }^{b}$ Department of Building Structures, Faculty of Civil Engineering, Czech Technical University in Prague, \\ Thakurova 7, 16629 Prague 6, Czech Republic \\ * corresponding author: havrlik.michal@seznam.cz
}

ABSTRACT. This article is focused on protection of wooden materials by using nanofibrous textiles with biocidal addition, which continues on the work of a group at the Center for Nanotechnology at the Faculty of Civil Engineering in the CTU. Timber is a natural material which is predisposed for biodegradation and therefore it is essential to study suitable and effective protection against microorganisms. Wood is a material susceptible to biological corrosion and therefore it is necessary to protect it.

The study compares biocidal efficiency of polymer solution as a coating and as a layer from nanofiber textiles. We used polyvinyl alcohol (PVA) as a basic polymer which was enriched by substances from commercial Lignofix E - profi, solution of $\mathrm{CuSO}_{4} \cdot 5 \mathrm{H}_{2} \mathrm{O}$ and $\mathrm{AgNO}_{3}$ and finally colloidal silver as an example of nanoparticles. The final concentration of the biocidal substance was 1 (V/wt) $\%$ in fiber. The nanofiber textiles are produced on the device Nanospider NS LAB 500 (Elmarco, CR) on cylinder rotating electrode.

The study was divided into two parts, the first being an agar plate test and the second a test on samples from timber. The mixture of mold was used as the model organism. (Alternaria tenuissima, Pochonia bulbiosa, Trichoderma viride and Acremonium sclerotigenum).

Comparison of efficiency between the polymer paint and nanofiber textiles showed no difference. The best results were shown by PVA with an addition of substances from the commercial biocidal treatment Lignofix-E Profi on the agar plate. The difference of result was shown on timbre samples, finding that the best results were with treatment by PVA doped by Silver nitrate. The anticipated results were shown by treatment with non-doped PVA, which does not have any fungicidal protective effect.

KEYWORDS: PVA; wood; fungicidal protection; mold; electrospinning; nanofiber textiles..

\section{INTRODUCTION}

Wood belongs to the most broadly applied organic building materials. Timber without any protection treatment is degraded by many biological pest and abiotic agents as water, moisture or change of temperature that cause changes their mechanical, aesthetic, physical and other properties. The important biological pests of wood are wood decaying fungi, mold and bacteria.

Fungi are the most occurring biological agents on timber and wood decaying fungi are the most danger pests of all, they can destroy the whole wooden structure. The protection and remediation against wood decaying fungi is a complicated and difficult process. If the timber is infected by them, the remediation of timber in building is nearly impossible without removed infected wooden parts. By the way, there are frequently found microscopic filamentous fungi (in common speech mold) at first, on which this article is focused on. Molds develop and grow most often on the surface layer of organic or inorganic substrates 1 .
Filiform formation is the basic part of mold, called hyphae. The mycelium is created by a lot of hyphae. Mycelium is very unstable and it can contaminate other surfaces and objectives. This is the origin of its reproduction, followed by growth of hyphae [2]. Mold for its growth needs suitable ambient conditions. A sufficient wet substrate is the first of them. The air humidity should be near $100 \%$. The suitable temperature for the development of mold is about $27-37^{\circ} \mathrm{C}$ and the $\mathrm{pH}$ between 5 and 7 [2].

Currently, the problem with biological degradation of timber are very frequently discussed by expert from civil engineering and architecture. This is caused by interested in ecological and natural living with usage renewable resources and building materials. The contemporary people have demanded high standard of inner wellbeing and the possibilities of design construction cannot protect building block of timber without additional support chemical biocidal treatment. This human idea is led to answer of question about balance between efficiency of biocidal treatment and human health. This question is connected with type of chemi- 

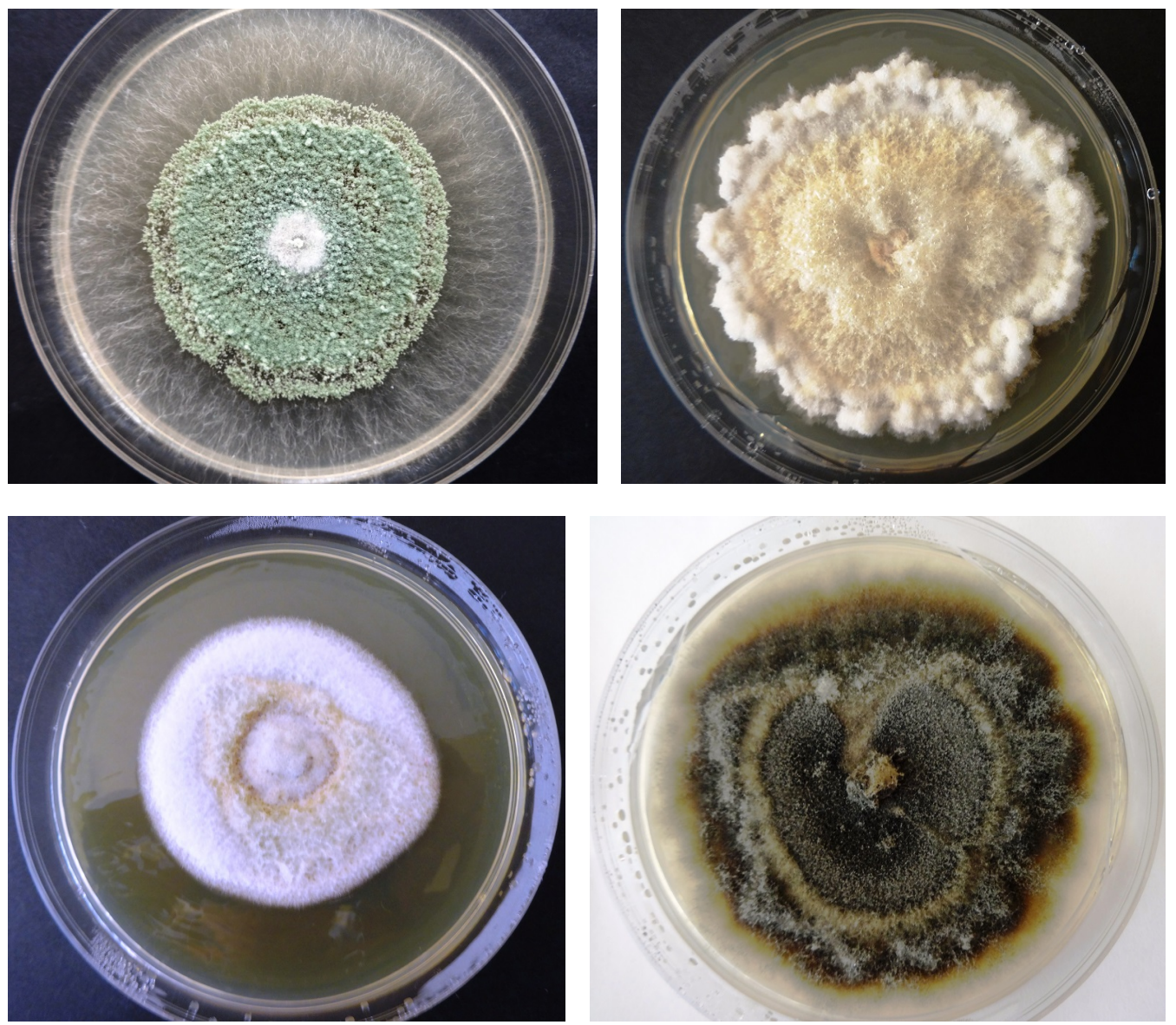

Figure 1. From left top: Trichoderma viride, Acremonium sclerotigenum. From left bottom: Pochonia bulbiosa, Alternaria tenuissima.

cal compounds, their concentration, and their anchorage in coat of building and so on. Contemporary law is placed demand on usage secure compounds for human and without changes to surrounding environment and species diversity.

\section{THE EXPERIMENTAL PART}

The protection of construction wood against biological degradation is realized by many a conventional methods such as painting, dipping, impregnation, etc. Novel method which is plentiful studied, is nanotechnology. This technology enable another way for protection of building materials include timber or cementbased materials [3] with usage lower concentration and with successively leached of efficiency agents. We are assumed that some forms on this base might be very suitable for the protection of wood also. Nowadays, many efficiently agents are prohibited for their bad consequence for surrounding environment and therefore it is necessary to look for a novel protection methods. Nanotechnology could be a new functional way to protect building materials [4, 5].

Nanofiber textiles are being used in medicine, electro optic and in another branch. There are began used in civil engineering particularly for their hydrophobic properties combined with high breathability [6].
The nanofiber textiles can used as a scaffold for carrying bioactive substance which is incorporated by nucleation [7] or direct in production. It may take the properties of supplement in/or nanofiber. The one of the highest cited and presented biocidal agents against wood deteriogens are ions of silver and copper. Their biocidal properties are depended on their concentration [8] Silver ion is widely used for their antibacterial properties from century and it is safe for human organism and it can used as a base for biocidal treatment against fungi or bacteria [9].

These experiments are focused on compared fungicidal properties of polymer solution doped by biocidal additives on plate tests and subsequently on building block from spruce. The second part is dealt preparing nanofiber textiles from same polymer solution and compare their fungicidal properties in same adjusting of experiments.

\section{Materials AND Methods}

\subsection{Production of PVA solution}

The base polymer which we used in this work, is a polyvinyl alcohol (PVA). The PVA is a white powdery substance of crystalline character with a wide industrial application [10]. The basic polymer solution had following content: $375 \mathrm{~g} 16 \%$ PVA (Sloviol 

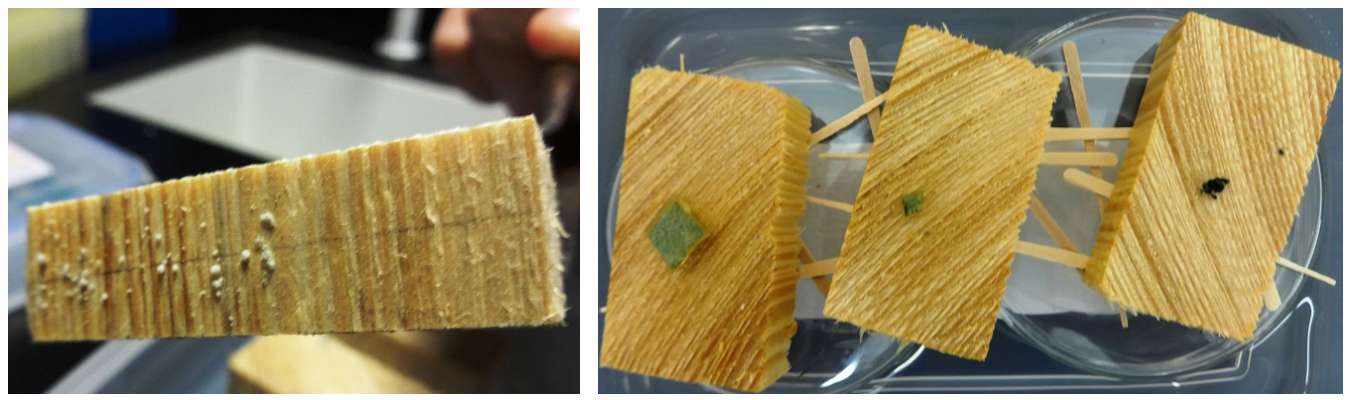

FiguRE 2. From left: Mold inoculation through immersion, 5 days after inoculation, inoculation mold with cut outs.

\begin{tabular}{|c|c|c|c|}
\hline Signification & Material & Type of ions & $\begin{array}{c}\text { Mass concentration in } \\
\text { solution [\%] }\end{array}$ \\
\hline PS (Pure PVA) & PVA - solution & - & - \\
\hline AS (PVA + Ag) & PVA - solution & $\mathrm{Ag}^{+}$ & 0,25 \\
\hline CS (PVA + Cu) & PVA - solution & $\mathrm{Cu}^{+}$ & 0,25 \\
\hline ACS (PVA + Ag + Cu) & PVA - solution & $\mathrm{Cu}^{+}+\mathrm{Ag}^{+}$ & 0,25 \\
\hline CoAS (PVA + Col. Ag) & PVA - solution & Colloidal $\mathrm{Ag}^{+}$ & 20 PPM \\
\hline $\begin{array}{c}\text { BS (PVA + Lignofix E- } \\
\text { Profi) }\end{array}$ & PVA - solution & Lignofix E - Profi & 0,25 \\
\hline
\end{tabular}

TABLE 1. List of the PVA solutions, including biocidal agents.

\begin{tabular}{|c|c|c|c|}
\hline Signification & Material & Type of ions & $\begin{array}{c}\text { Mass concentration in } \\
\text { nanofiber [\%] }\end{array}$ \\
\hline PT (Pure PVA) & PVA - Naofibre textile & - & - \\
\hline AT (PVA + Ag) & PVA - Naofibre textile & $\mathrm{Ag}^{+}$ & 2 \\
\hline CT (PVA + Cu) & PVA - Naofibre textile & $\mathrm{Cu}^{+}$ & 2 \\
\hline ACT (PVA + Ag + Cu) & PVA - Naofibre textile & $\mathrm{Cu}^{+}+\mathrm{Ag}^{+}$ & 2 \\
\hline COAT (PVA + Col. Ag) & PVA - Naofibre textile & Colloidal $\mathrm{Ag}^{+}$ & 167 PPM \\
\hline BT (PVA + Lignofix E-Profi) & PVA - Naofibre textile & Lignofix E - Profi & 2 \\
\hline
\end{tabular}

TABLE 2. List of the PVA nanofiber textiles, including biocidal agents.

R16, Fichema), $4.4 \mathrm{~g}$ Glyoxal, $3 \mathrm{~g} 80 \% \mathrm{H}_{3} \mathrm{PO}_{4}$ and a demineralized water filled up to $500 \mathrm{~g} \mathrm{[11.} \mathrm{The} \mathrm{bio-}$ cidal agents (Tab. 1) was stirred into basic polymer solution. We selected following agents: commercial biocide Lignofix E - Profi, pentahydrate copper sulfate $\left(\mathrm{CuSO}_{4} \cdot 5 \mathrm{H}_{2} \mathrm{O}\right)$ as example ion of copper, silver nitrate $\left(\mathrm{AgNO}_{3}\right)$ as example ion of silver, colloidal silver as example of nanoparticles and combination of silver nitrate and pentahydrate copper sulfate for evaluation of potential synergic enhance their biocidal properties. The final mass of agents in basic solution was in range $0.25 \mathrm{wt} \%$.

\subsection{Produce of NANOFiber textiles}

The nanofiber textile was produced by using of electrostatic spinning device - Nanospider NS LAB 500 S (Elmarco, Czech Republic) in the Center for Nanotechnology at the Faculty of Civil Engineering in the Czech Technical University and in the joint laboratory of Institute of Physics ASCR and FCE CTU. The setup of device is same as the previous article [12]. The fabrics were produced in the form of monolayers and the weight per square meter $5 \mathrm{~g} / \mathrm{m}^{2}$. The mass concentration of biocidal agents in fiber was around $2 \%$, except CoAS, it was 167 ppm.

\subsection{MODEL ORGANISM}

Microscopic filamentous fungi were used in this experiment as a model organism. This organism was obtained by swabbing in situ from building occur in Czech Republic. There was identified following consortium Alternaria tenuissima, Pochonia bulbiosa, Trichoderma viride and Acremonium sclerotigenum.

\subsection{Plate experiment}

The evaluation of fungicide properties of polymer solution and nanofiber textiles was made on the malt agar (Merck, USA). The model organism is applied as 100 ul mixture of fungi (Alternaria tenuissima, Pochonia bulbiosa, Trichoderma viride and Acremonium scle- 


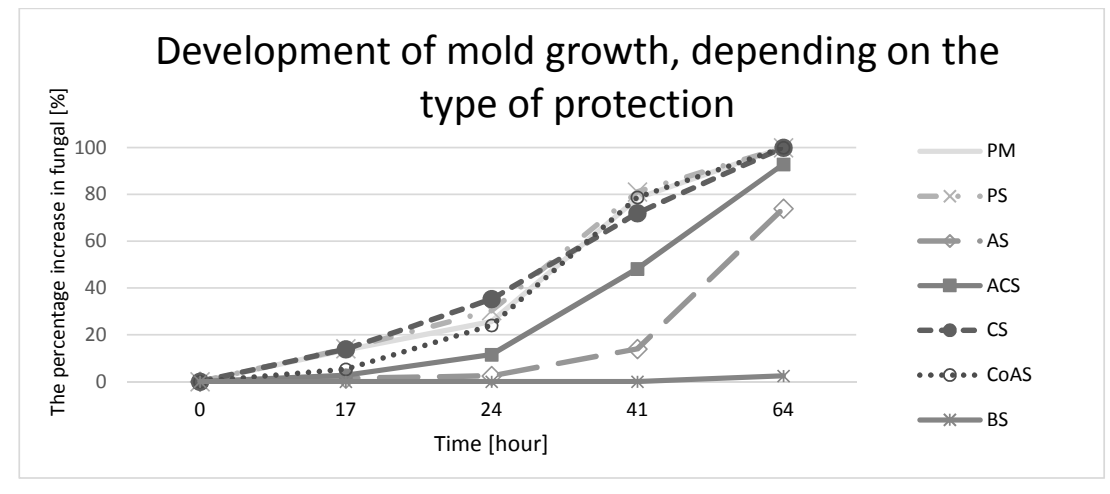

Figure 3. Development of fungi in Petri dishes.

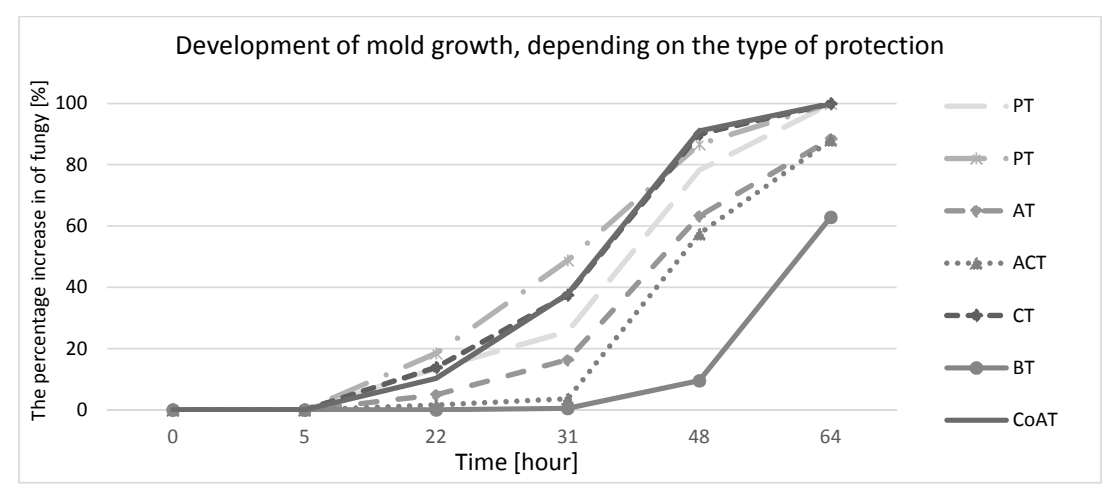

Figure 4. Development of fungi in Petri dishes.

rotigenum) in physiological solution by spread over whole plate. The samples was placed in the center.

\subsection{EXPERIMENT ON BUILDING BLOCK OF TIMBER}

The second experiment was used building block of timber. We had chosen spruce for their common usage in Czech civil engineering. The wooden surface was inoculated by three methods. The first on was by immersing of sterile block into fungi mixture (as in plate experiment) for $5 \mathrm{~s}$ as. The second type of inoculation was by mixture of mold on malt agar. The cut had square shape with size 10 and $1 \mathrm{~mm}$. The last method was used smear from the agar plate and it was placed on wooden samples. The cultivation was made in the plastic boxes with optimal conditions for mold growth, $28 \pm 2{ }^{\circ} \mathrm{C}$ temperature and $\mathrm{RH}$ around $98 \%$ for 5 days.

These three methods have been implemented for monitoring the impact of agar for molds growth. The cut outs are shown in (Fig. 2).

Four basic experiments have been performed to study antibacterial qualities of nanofiber textiles.

\subsection{FUNGICIDAL ACTIVITY OF POLYMER SOLUTION ON AGAR PLATE}

The aim of this experiment was demonstrate the fungicidal efficiency of the polymer solutions doped biocide ions. The prepared polymer solution was homogenized by ultrasonication for 20 minutes and placed into Petri dish in volume $100 \mu \mathrm{l}$ and spread over whole surface. The drying was in $37^{\circ} \mathrm{C}$ for 1 hour. The agar plate without polymer solution was used as positive control. Every agar plate was inoculated $20 \mu \mathrm{l}$ mixture of model organisms and it was incubated at $28 \pm 2{ }^{\circ} \mathrm{C}$ temperature and $\mathrm{RH}$ around $98 \%$. The evaluation was recorded every twelfth hour during 64 hours. The results are recorded in Fig. 3 .

\subsection{FUnGICIDAL ACTIVITY OF NANOFIBER TEXTILES ON AGAR PLATE}

The next experiment want demonstrated the fungicidal efficiency nanofiber textiles doped biocide ions. The mixture of model organism was dripped on center on agar plate and covered by nanofieber textile with circle shape with diameter $20 \mathrm{~mm}$. The results was classified as a percentage of increase of growth fungi on agar plate during 64 hours. The results are shown in Fig. 4 .

\subsection{FUNGICIDAL ACTIVITY OF POLYMER SOLUTION ON WOODEN BLOCKS}

We used sterilized the building block of timber with size $50 \times 30 \times 15 \mathrm{~mm}$. The biocidal treatment was made by paint of polymer solution (same as a 3.1, the samples named in Tab. 1). The drying was in $24 \pm 2{ }^{\circ} \mathrm{C}$ temperature and $\mathrm{RH}$ around $60 \%$ during 24 hours. The experiment was made in three repeated from each type of solution. In respond to previously results, we did not applied colloidal silver (CoAS) 


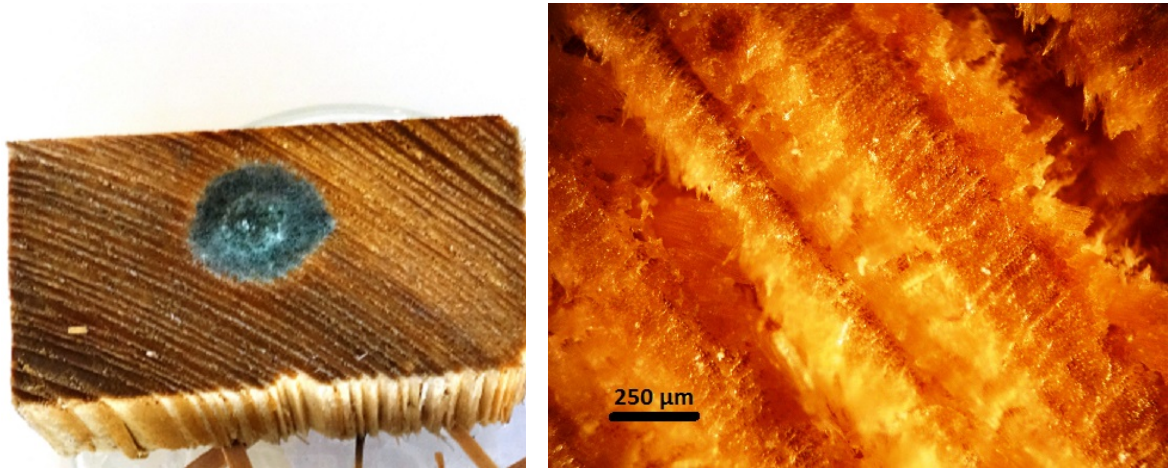

FiguRE 5. From left: Macro picture of the sample, micro shot focuses on a clean part of the sample.
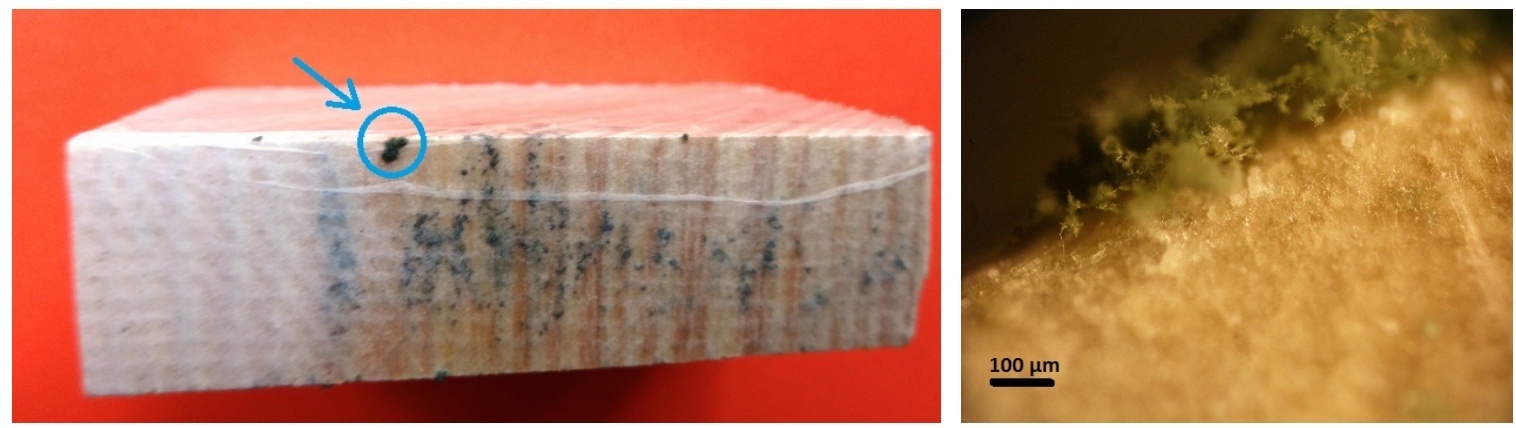

FiguRE 6. Growth of mold on the outside of the nanofiber textile sample of pure PVA day 32.

for their ineffective fungicidal properties in this low concentration. The positive control was used the building block of wood without protection. Further, the samples were inoculated by fungi cut with residue of malt agar. The incubation was under optimal condition $\left(28 \pm 2{ }^{\circ} \mathrm{C}\right.$; $\left.\mathrm{RH} 98 \%\right)$. The growth of molds was monitored during 39 days.

\subsection{FungiCIDAL ACTIVITY OF NANOFIBER TEXTILES ON WOODEN BLOCKS}

The samples was inoculated by immersion into mixture of fungi and pre-incubated under same condition as a whole experiment for 5 days. The nanofiber textile fungicidal protection was applied after visual growth mycelium in 5th day (See Fig. 2). The nanofiber textile samples was used same as above. The wooden samples was coated nanofiber textile. The coverage of wood by nanofiber textiles was complicated due to the very small mechanical resistance of the fabric itself without a spunbond. The samples were placed under conditions $28 \pm 2{ }^{\circ} \mathrm{C}$ temperature and $\mathrm{RH} 98 \%$. The whole experiment was observed for 39 days.

\section{Results}

\subsection{FungiCIDAL ACTIVITY OF POLYMER SOLUTION ON AGAR PLATE}

The experiment was designed to demonstrate fungicidal properties of polymer solutions and equivalent nanofiber textiles. The evaluation was based on changes of fungi growth and it was calculated as percentage increase. The highest efficiency of protection evinced polymer solution doped Lignofix E - Profi which almost has restricted fungi growth. The samples AS and ACS showed slower growth. The remaining samples almost show small or no fungicidal effects. The samples with pure PVA showed interesting result. This polymer brought in nutrient for fungi and due it had worse efficiency than wood without protection. This is due to the fact that the PVA contains carbon and mold could it metabolize. The results are shown in Fig. 3 .

\subsection{FungiCIDAL ACTIVITY OF NANOFIBER TEXTILES ON AGAR PLATE}

The most effective protection was achieved by usage sample BT - Lignofix E - Profi. The lower effective component of PVA appears to colloidal silver - CoAT. The pure sample of PVA did not demonstrate a biocide activity and it works like barrier.

\subsection{FUNGICIDAL ACTIVITY OF POLYMER SOLUTION ON WOODEN BLOCKS}

In the first stage of the experiment, the assumption was confirmed, that fastest fungi growth was in experiment with the greatest amount residue of agar (cut $1 \times 1 \mathrm{~cm}$ ). The protected sample reflected greater increase on a sample of cut $1 \times 1 \mathrm{~cm}$ because unprotected wood soaked agar into wood. The evaluation of fungicidal efficiency of protection by nanofiber textiles was performed by eye because the growth mycelium in macroscopic level. The photo documentation was performed in definite interval for 39 days. The final process of growth is recorded in the (Tab. 3). The 


\begin{tabular}{|c|c|c|c|c|c|c|c|c|c|c|c|c|c|c|c|c|}
\hline \multirow{3}{*}{ Date } & \multirow{3}{*}{$\begin{array}{c}\text { Number } \\
\text { of days }\end{array}$} & \multicolumn{5}{|c|}{ WITHOUT PROTECTION } & \multicolumn{5}{|c|}{ PS } & \multicolumn{5}{|c|}{ AS } \\
\hline & & \multicolumn{2}{|c|}{ agar } & \multicolumn{3}{|c|}{ wood } & \multicolumn{2}{|c|}{ agar } & \multicolumn{3}{|c|}{ wood } & \multicolumn{2}{|c|}{ agar } & \multicolumn{3}{|c|}{ wood } \\
\hline & & 1 & 2 & 1 & 2 & 3 & 1 & 2 & 1 & 2 & 3 & 1 & 2 & 1 & 2 & 3 \\
\hline 17.10. & TP & - & - & - & - & - & - & - & - & - & - & - & - & - & - & - \\
\hline 18.10. & APL & - & - & - & - & - & - & - & - & - & - & - & - & - & - & - \\
\hline 21.10. & 3 & $\mathbf{x}$ & $x$ & - & - & - & XX & - & $x$ & - & - & - & - & - & - & - \\
\hline 23.10. & 5 & $\mathbf{x}$ & $x$ & $x$ & - & - & $\mathbf{x x}$ & - & $x \mathbf{x}$ & - & - & - & - & - & - & - \\
\hline 25.10. & 7 & $\mathbf{x}$ & $\mathbf{x}$ & $\mathbf{x}$ & - & - & $\mathbf{x X}$ & - & $x \mathbf{x}$ & - & - & $\mathbf{x}$ & - & - & - & - \\
\hline 29.10 . & 11 & $x$ & $x$ & $\mathbf{X X X}$ & - & - & $x x$ & - & $x X$ & - & - & $x X$ & - & - & - & - \\
\hline 31.10. & 13 & $\mathbf{x}$ & $x$ & $\mathbf{X X X}$ & $x$ & $x$ & XX & - & $X X$ & - & - & $X X$ & - & - & - & - \\
\hline 5.11 . & 18 & $\mathbf{x}$ & 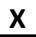 & $\mathrm{XXX}$ & $\mathbf{X X X}$ & $x X$ & $x X$ & - & $X X$ & - & - & $X X$ & - & - & - & - \\
\hline 12.11. & 25 & $\mathbf{x}$ & $\mathbf{x}$ & $\mathbf{x x x}$ & $\mathbf{x x x}$ & $x x$ & $\mathbf{x X}$ & $x$ & $x x$ & $\mathbf{x x}$ & - & $x x$ & - & - & - & - \\
\hline 19.11. & 32 & $\mathbf{x}$ & $\mathbf{x}$ & $\mathbf{x X X}$ & $\mathbf{X X X}$ & $x x$ & $\mathbf{x X}$ & $\mathbf{x}$ & $x \mathbf{x}$ & $\mathbf{X X X}$ & $\mathrm{xxX}$ & $\mathbf{x x}$ & - & - & - & - \\
\hline 26.11. & 39 & $\mathbf{x}$ & $x$ & $X X X$ & XXX & $x x$ & XX & $x$ & $X X$ & $\mathbf{X X X}$ & 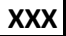 & $x X$ & - & - & - & - \\
\hline
\end{tabular}

\begin{tabular}{|c|c|c|c|c|c|c|c|c|c|c|c|c|c|c|c|c|}
\hline \multirow{3}{*}{ Date } & \multirow{3}{*}{$\begin{array}{l}\text { Number } \\
\text { of days }\end{array}$} & \multicolumn{5}{|c|}{ CS } & \multicolumn{5}{|c|}{ ACS } & \multicolumn{5}{|c|}{ BS } \\
\hline & & \multicolumn{2}{|c|}{ agar } & \multicolumn{3}{|c|}{ wood } & \multicolumn{2}{|c|}{ agar } & \multicolumn{3}{|c|}{ wood } & \multicolumn{2}{|c|}{ agar } & \multicolumn{3}{|c|}{ wood } \\
\hline & & 1 & 2 & 1 & 2 & 3 & 1 & 2 & 1 & 2 & 3 & 1 & 2 & 1 & 2 & 3 \\
\hline 17.10. & TP & - & - & - & - & - & - & - & - & - & - & - & - & - & - & - \\
\hline 18.10. & APL & - & - & - & - & - & - & - & - & - & - & - & - & - & - & - \\
\hline 21.10 . & 3 & $x x$ & - & - & - & - & $\mathbf{X X}$ & - & - & - & - & - & - & - & - & - \\
\hline 23.10 . & 5 & $x X$ & - & - & - & - & XX & - & - & - & - & - & - & - & - & - \\
\hline 25.10 & 7 & $x x$ & - & - & - & - & $x x$ & - & - & - & - & $x$ & - & - & - & - \\
\hline 29.10 . & 11 & $x x$ & - & - & - & - & $\mathbf{X X}$ & - & - & - & - & $x x$ & - & - & - & - \\
\hline 31.10. & 13 & $x x$ & - & - & - & - & $x X$ & - & - & - & - & $X X$ & - & - & - & - \\
\hline 5.11. & 18 & $x x$ & - & $x X$ & - & - & $x x$ & - & - & - & - & $x x$ & - & - & - & - \\
\hline 12.11 & 25 & $x x$ & - & $x X$ & - & - & $\mathbf{X X}$ & - & - & - & - & $x x$ & - & $x$ & - & - \\
\hline 19.11. & 32 & $x x$ & $x$ & $\mathrm{XXX}$ & $\mathrm{XXX}$ & $x$ & $\mathbf{X X}$ & - & - & - & - & $x x$ & $x$ & $x x$ & - & - \\
\hline 26.11. & 39 & $x x$ & $x$ & XXX & XXX & $\mathrm{XXX}$ & $\mathbf{X X}$ & - & - & - & - & $x x$ & $x$ & $x x$ & $x$ & - \\
\hline
\end{tabular}

Note: 1 - cutout $1 \times 1 \mathrm{~cm}, 2$ - cutout $1 \times 1 \mathrm{~mm}, 3$ - smear Explanation:

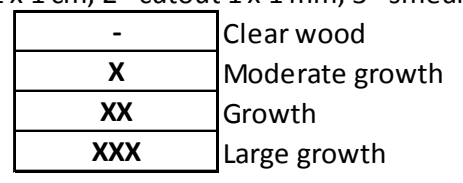

TP - time painting

APL - time application Large growth

TABLE 3. Evaluation of the growth of the mycelium on each samples during 39 days. The classification was divided to four group: Clear - without growth, Moderate growth $-10 \%$ covered, Growth $-30 \%$ covered, Large growth mycelium covered more than $60 \%$.

first evidence of fungi growth was on the sample PS (pure PVA solution) around the third day. The worst biocidal properties had showed copper sulphate pentahydrate. The most efficiency had showed solution with addition of silver ions. We had checked the sample with best protection by microscopy observation. The fungi had grown only on residue of agar but the wood sample was uninfected after 39 days.

The ACS sample showed the same properties on a macroscopic scale as a sample AS. Microscopic analysis of the sample ACS showed fungal growth even after a clean timber. The visible of molds in macro scale was only a question of time. This result can indicate that copper in a low concentration can influences a fungicidal activity of the silver. We will interested in it in next exploration

\subsection{FungiCIDAL ACTIVITY OF NANOFIBER TEXTILES ON WOODEN BLOCKS}

In the last experiment, we evaluated fungicidal properties of nanofiber textiles doped biocidal ions on wood samples which was inoculated by mold direct on wood. It was observed of penetration of fungi mycelium through textiles. The first symptom of growth through had shown sample PT after 32 days (See Fig. 6) The textiles made from pure PVA had shown no fungicidal activity identically previous results. The individual hyphae of fungi grown into structure of nanofiber textiles but did not get over it. This result supposed good efficiency that in case if this protection is used to healthy timber in contaminated environment. The wood with this protection will not be degraded. The growth mold on the outside of the sample $\mathrm{PT}$ is origin rather from the external environment. The more problem was shown with me- 
chanical stability of nanofiber textiles and with their application than with their efficiency.

Fungicidal properties of the PVA fabric has not been shown. This nanofiber textile has used only as a scaffold for carry biocidal agents. It will be necessary repeat this experiment with longer duration than 40 days for confirmation of fungicidal activity as a remediation treatment. We demonstrated only barrier properties for 40 days.

\section{Discussion AND CONCLUSION}

\subsection{SOlutions AND TEXTILES}

The protection by solution is evinced lower antifungal efficiency to compare with equal based nanofiber textiles. It is depended on concentration of added ions. The solution contains the $0.25 \%$ ions and the nanofiber textiles have $2 \%$ due evaporated water during electrospinning preparation. The polymer solution has not limited the maximum amount of biocidal supplements. On the other hand, the nanofiber textiles basic solution has limited concentration up to $3.5 \%$. If it is re-counted to concentration in nanofiber, it will be up to $22 \%$ in fiber. The other factor of usage nanofiber textiles is their difficult application in real construction. The polymer solution is applied very easily and it is stable. The disadvantage of polymer solution is in uniformly distribution in volume and the easy leaching.

\subsection{PVA}

The fungicidal properties of polymer solution is limited and it is determined by low concentration supplement and supply of carbon for microorganisms. This effect was found in both types of protections.

\subsection{Protective Biocide ions}

The efficiency of copper (copper sulphate pentahydrate) was the biggest surprise of the experiment and it is identical with copper fungicidal properties presented in literature [5, 13. The amount of fungicidal effect is depended on concentration and if it is used low concentration it will support growth of fungi.

Silver nitrate confirmed biocide activity. The activity of silver is monitored form very low concentration

The last biocidal agent was Lignofix E - Profi. The manufacturer's recommended concentration is $1: 9$. We used concentration around $1: 100$ and this concentration had still fungicidal activities.

\subsection{Summary}

The biocide efficiency of ions in solutions, and textiles were studied. The highest fungicidal effect was achieved support by Lignofix E - Profi in plate experiments. In some cases, the solution form has killing effect to fungi. Other agents showed lower reactivity than Lignofix E - Profi, silver ions belong to the best from other ones. The pure PVA does not confirmed biocide activity. The barrier properties of the fabric were not confirmed, due to of a strong presence of mold growth on agar plate. The second growth medium was spruce. The protection by solution doped silver ions achieved the best result. The pure PVA has not fungicidal protective effect for wood samples. The experiment had proposed with suitable condition for growth fungi which is not occur in building construction. Therefore it should not expect total killing effect for fungi. Overall, this work confirmed fungicidal efficiency of selected agents in form of polymer solution as well as in textiles and it shown this activity even at low concentration.

\section{ACKNOWLEDGEMENTS}

This work was supported by "Grand Application of advanced technologies in modern engineering" SGS14/111/OHK1/2T/11. The work has been performed within framework of Joint Laboratory of Nanofibers Technology of Institute of Physics ASCR and Faculty of Civil Engineering CTU in Prague.

\section{REFERENCES}

[1] R. Wasserbauer, Biologické znehodnocení staveb [Biological Damage of Structures]. ABF ARCH: Praha, Prague, 2000.

[2] O. Fassatiová, Plísně a vláknité houby v technické mikrobiologii:(Příručka k určování). SNTL, Prague, 1979.

[3] P. Demo, A. Sveshnikov, Š. Hošková, D. Ladman, and P. Tichá, "Physical and Chemical Aspects of the Nucleation of Cement-Based Materials," Acta Polytech., vol. 52, no. 6, 2012.

[4] P. Ryparová, Z. Rácová, P. Tesárek, and R. Wasserbauer, "The Antibacterial Activity of Nanofiber Based on Poly-vinyl-alcohol (PVA) Doped by Metal," Nanocon10, p. 23 - 25, 2012.

[5] P. Ryparová, R. Wasserbauer, P. Tesárek, and Z. Rácová, "Preparation of Antimicrobial Treatment Interiors Using Nanotextiles,"Central Europe towards Sustainable Building, 2013.

[6] P. Gibson, H. Schreuder-Gibson, and D. Rivin, "Transport Properties of Porous Membranes Based on Electrospun Nanofibers," Colloids Surf. Physicochem. Eng. Asp., vol. 187-188, p. 469-481, Aug. 2001.

[7] P. Demo, Z. Kožíšek, and R. Šášik, "Analytical Approach to Time Lag in Binary Nucleation," Phys. Rev. E, vol. 59, no. 5, p. 5124, 1999.

[8] A. C. S. Hastrup, F. Green III, C. A. Clausen, and B. Jensen, "Tolerance of Serpula Lacrymans to Copper-based Wood Preservatives," Int. Biodeterior. Biodegrad., vol. 56, no. 3, p. 173-177, Oct. 2005.

[9] A. V. Vegera and A. D. Zimon, "Synthesis and Physicochemical Properties of Silver Nanoparticles Stabilized by Acid Gelatin," Russ. J. Appl. Chem., vol. 79, no. 9, p. 1403-1406, Sep. 2006.

[10] J. L. Gardon, "Encyclopedia of Polymer Science and Technology," Mark HF, p. 833-863, 1965.

[11] P. Tesárek, V. Nezerka, R. Toupek, T. Pachý, and P. Ryparová, "Macro Mechanical Testing of Nanofibers: Tensile Strength," Proceedings of the 50th Annual Conference on Experimental Stress Analysis, p. 465-468, 2012. 
[12] P. Tesárek, P. Ryparová, Z. Rácová, V. Králík, J.

Němeček, A. Kromka, and V. Nežerka, "Mechanical

Properties of Single and Double-Layered PVA

Nanofibers," Key Eng. Mater., vol. 586, p. 261-264, 2014.

[13] Z. Rácová, P. Hrochová, and P. Ryparová,

"Treatment of Timber by Nanofiber Fabric with Biocide

Compound," in Advanced Materials Research, vol. 1000,

p. 154-157, 2014. 